\title{
TRIBUTE TO T.W. ANDERSON
}

\author{
Peter C.B. Phillips \\ Yale University, University of Auckland, \\ University of Southampton, Singapore Management University
}

December 16, 2016

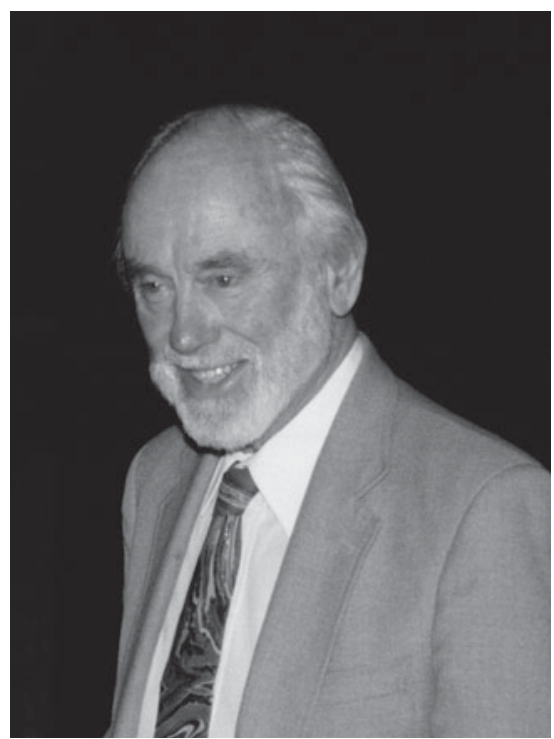

Ted Anderson, Fort Lauderdale 1998 (photograph: courtesy of Simo Puntanen)

In this issue, Econometric Theory is proud to include the last scientific publication of Professor T. W. Anderson. Professor Anderson, who was universally and affectionately known as Ted to all his colleagues, sadly passed away on September 17, 2016 after an astonishing career that spanned beyond seven decades. Within the statistics and econometrics professions Ted was a titan who stood humbly and confidently astride both communities, an intellectual giant whose original research and pedagogical writings continue to inspire new generations of scholars.

Ted's article that is published in this issue was submitted in 2012 and, following the usual review process and some later revisions, was re-submitted with follow-up correspondence on 2 September, 2016 when Ted was 98 years of age, only a few days before he died. The paper addresses a subject that had engaged

My thanks to Olav Bjerkholt for helpful comments on the original draft of this tribute. Research support from the NSF under SES 12-85258 is gratefully acknowledged. 
Ted's attention since his appointment to the Cowles Commission in the fall of 1945 as a newly minted Ph.D in mathematical statistics from Princeton and which connects with his doctoral research interests at Princeton on the non-central Wishart distribution.

In 1945 the Cowles Commission was studying issues of identification in simultaneous equations models and exploring the use of Gaussian maximum likelihood techniques for their statistical estimation. The leaders of the Cowles research team were Jacob Marschak, the Cowles Director, and Tjalling Koopmans, then a Research Associate. Events moved quickly in the fall of 1945 and are related in detail by Bjerkholt (2015). Abraham Wald at Columbia brought Ted to Marschak's attention and following this introduction Ted was hired to assist the Cowles Commission's methodological research on simultaneous equations. Full system methods of estimation had been developed and Ted was charged with the primary research project to investigate the use of such methods on a single equation, using only the partial identifying information on that particular equation. The hope was that such a 'limited information maximum likelihood' (LIML) method would simplify computation, facilitate practical implementation, and enable modelers to focus on the properties of a single equation at a time.

Cowles could have made no better appointment. A sustained research effort ensued that involved insights en route from a Cowles research consultant, Abe Girshick, about a 'reduced form approach'. The final outcome was a brilliant joint paper by Ted and Herman Rubin that was published in the Annals of Mathematical Statistics in 1949, entitled "Estimation of the parameters of a single equation in a complete system of stochastic equations". This article gave birth to LIML, a likelihood ratio test of overidentification, and the Anderson-Rubin test, methods that successfully met the Cowles Commission project goals and have since proved remarkable for their longevity. Almost seventy years on we continue to use these methods, explore their properties, and build on their inferential foundations. Ted's final paper does just this by establishing a key 'Pareto optimality' property of the likelihood ratio test in a simple LIML setting. In his earlier 2015 ET paper that reminisced on his association with Trygve Haavelmo and recounted the research environment of the Cowles Commission, Ted extolled the merits of LIML with endorsements of its multiple advantages. Somewhat ruefully given the enormous evidence in favor of LIML, Ted questioned the profession in the original version of his article, asking "why have econometricians been reluctant to use the LIML estimator". Why indeed, I would echo!

Ted's connection with the journal Econometric Theory goes back to 1983, when I asked him if he would accept appointment as an Advisory Editor of this new journal which was then in the making. One of the missions of ET was to establish a productive connective bridge between mathematical statistics and econometrics. In many ways, Ted was the human embodiment of this connective tissue. Throughout his long career, Ted's work conjoined the disciplines in new and unexpectedly productive ways that strengthened the methodological fabric of 
econometrics and widened the empirical perspectives of statistical research through a multitude of diverse economic applications.

Ted's personal conjunction of the disciplines began with his work for the Cowles Commisssion and the 1949 LIML paper where the 'Cowles Commission method', as it was later called by Malinvaud (1964), opened up new avenues of applied research by virtue of its simplicity and its promising asymptotic properties. Later in the 1970s, Ted went on to research the finite sample properties of LIML and its sister method LIMLK (simply LIML with a known reduced form error covariance matrix) which figures prominently in his final published paper. The research revealed how well this method worked in relation to instrumental variables and two stage least squares, a method that Ted was fond to point out was discovered en route to LIML during the research of the 1940s. Cognizant of the importance of statistical inference, the original LIML paper also developed a finite sample approach to testing and confidence interval construction, one that has attracted extensive modern interest. This attention has in turn breathed new vigor into the Anderson-Rubin style of testing, particularly in cases of weak identification and the recent econometric analysis of treatment effects.

How remarkable an author it is who can cite a famous article of his own that was published 69 years earlier. Such a span of years exceeds many a normal human lifetime. For Ted, seven decades lay comfortably within his career's astonishing compass. If he had cited his earliest published work (two papers in the Annals of Mathematical Statistics in 1943) or the paper (Anderson and Girshick, 1944) on the Wishart distribution with reduced rank noncentrality matrix - another notable accomplishment that initiated a major research agenda on noncentral matrix variate distribution theory - then the span of time would reach a full three quarters of a century. How few individuals in the history of scientific endeavour can match such a strikingly memorable feat.

In opening a scholarly conversation with Ted that was published in 1986 in the ET Interview series, I wrote

The scope and diversity of his research in statistical theory is almost a phenomenon in itself. Sometimes it seems that wherever one turns in the subject, Ted's mark and influence is already firmly established. His books on multivariate analysis and time-series rapidly became accepted as major treatises and are now integral parts of the bookshelves of every statistician. His articles, like his books, have long established him as one of the best communicators in the statistics profession. His work is nothing short of exemplary, both in rigor and in exposition, and has been the fountainhead of entire fields of subsequent research. (Phillips, 1986)

Among these many field directions, it would be a travesty not to mention some avenues of Ted's research that have proved most influential in subsequent econometric work. In Anderson (1951), Ted introduced statistical tools for reduced rank 
regression, a topic that connected with his doctoral research and that now underpins major lines of work in nonstationary time-series with cointegrated variates. Ted's paper drew results from his Princeton thesis and delivered likelihood ratio tests as well as estimation methods and asymptotic developments. The present toolroom of econometric methods on reduced rank vector autoregressions and tests for cointegrating rank owes much to this foundational contribution.

Ted's early work in the 1940s and 1950s in time-series and factor analysis quickly established him as a leading innovator in both these fields. Amongst some of the world's prominent mathematicians like John von Neumann, Ted tackled the challenging time-series problem of finding the exact finite sample distribution of the serial correlation coefficient. His 1959 Annals of Mathematical Statistics paper on the asymptotic distribution of autoregressive estimates attracted wide attention for its development under minimal moment conditions and for his extensive analysis of explosive case limit theory, a subject that has stimulated recent interest in explosive behavior (Phillips and Magdalinos, 2007) and the econometric detection of bubbles in financial markets (Phillips, Wu, and Yu, 2011; Phillips, Shi and $\mathrm{Yu}, 2015)$. And factor analysis methods now figure prominently in high dimensional statistics, functional data analysis, and econometric forecasting as well as psychometrics.

Another early contribution in the 1950s (Anderson and Darling, 1952) paved the way for a rigorous asymptotic analysis of goodness of fit tests. This work produced the Anderson-Darling test and a limit distribution that was expressed in terms of a quadratic functional of a Gaussian stochastic process, giving one of the earliest applications of Donsker's functional limit theory for empirical processes and Mercer's eigenfunction representation of a continuous covariance kernel. The Anderson-Darling distribution itself and even more prominently the methodology of stochastic process limit theory have played a conspicuously important role in econometric research since the 1980s, with an equally influential impact on microeconometrics and time-series econometrics.

In the 1980's, Ted published two papers (Anderson and Hsiao, 1981, 1982) with his former student Cheng Hsiao that broke entirely new ground in panel data modeling. These papers demonstrated that, with use of a simple choice of instrumental variable, serious bias problems in dynamic panel models could be eliminated. This idea became the foundation stone of what quickly grew into a veritable cathedral of GMM econometric methodology for panel modeling, creating in the process a sub-discipline in itself with its own graduate courses and textbooks, and with tentacles of application reaching across many different sciences.

These articles, among so many others, form part of Ted's legacy to econometrics and they reward repeated readings. His textbooks of multivariate analysis and time-series are classics that provide masterful roadmaps of these subjects to students and researchers. Ted Anderson held dual titles as Professor of Statistics and Professor of Economics at Stanford. The links that his life and his research forged between these two disciplines are treasures that enrich us all. Whether colleagues, friends, former students, or scholars who know Ted only from his 
writings, we grieve his passing, celebrate his accomplishments, and endeavor to carry forward the traditions of excellence that his many contributions so firmly established in our subject.

\section{REFERENCES}

Anderson, T.W. (1943) On card matching. Annals of Mathematical Statistics 14, 426-435.

Anderson, T.W. (1951) Estimating linear restrictions on regression coefficients for multivariate normal distributions. Annals of Mathematical Statistics 22, 327-351.

Anderson, T.W. (1959) On asymptotic distributions of estimates of parameters of stochastic difference equations. Annals of Mathematical Statistics 30, 676-687.

Anderson, T.W. (2015) My Reminiscences of Trygve Haavelmo at the Cowles Commission. Econometric Theory 31, 180-192.

Anderson, T.W. \& D.A. Darling (1952) Asymptotic theory of certain 'goodness of fit' criteria based on stochastic processes. Annals of Mathematical Statistics 23, 193-212.

Anderson, T.W. \& M.A. Girshick (1944) Some extensions of the Wishart distribution. Annals of Mathematical Statistics 15, 345-357.

Anderson, T.W. \& C. Hsiao (1981) Estimation of dynamic models with error components. Journal of the American Statistical Association 76, 598-606.

Anderson, T.W. \& C. Hsiao (1982) Formulation and estimation of dynamic models using panel data. Journal of Econometrics 18, 47-82.

Anderson, T.W. \& H. Rubin (1949) Estimation of the parameters of a single equation in a complete system of stochastic equations. Annals of Mathematical Statistics 20, 46-63.

Anderson, T.W. \& D.S. Villars (1943) Some significance tests for normal bivariate distributions. Annals of Mathematical Statistics 14, 141-148.

Bjerkholt, O. (2015) Trygve Haavelmo at the Cowles Commission. Econometric Theory 31, 1-84.

Malinvaud, E. (1964) Méthodes Statistiques de l'Économétrie. Dunod.

Phillips, P.C.B. (1986) An interview with Professor T.W. Anderson. Econometric Theory 2, 249-288.

Phillips, P.C.B. \& T. Magdalinos (2007) Limit theory for moderate deviations from a unit root. Journal of Econometrics 136, 115-130.

Phillips, P.C.B., S. Shi, \& J. Yu (2015) Testing for Multiple Bubbles: Historical episodes of exuberance and collapse in the S\&P 500. International Economic Review 56, 1042-1076.

Phillips, P.C.B., Y. Wu, \& J. Yu (2011) Explosive behavior in the 1990s Nasdaq: When did exuberance escalate asset values? International Economic Review 52, 201-226. 